CLINICAL STUDY

\title{
Serum vascular endothelial growth factor levels in patients with medullary thyroid carcinoma
}

\author{
Maria João Bugalho ${ }^{1,4}$, Deolinda Madureira ${ }^{2}$, Carla Espadinha ${ }^{3}$, Ana Paula Font ${ }^{2}$ and Luís G Sobrinho ${ }^{1,4}$ \\ ${ }^{1}$ Serviço de Endocrinologia, ${ }^{2}$ Laboratório de Endocrinologia and ${ }^{3}$ Centro de Investigação de Patobiologia Molecular, Instituto Português de Oncologia de \\ Lisboa Francisco Gentil E.P.E., Rua Professor Lima Basto, 1099-023 Lisboa, Portugal and ${ }^{4}$ Faculdade de Ciências Médicas da Universidade Nova Lisboa, \\ 1169-056 Lisboa, Portugal \\ (Correspondence should be addressed to M J Bugalho; Email: mjbugalho@ipolisboa.min-saude.pt)
}

\begin{abstract}
Background: High levels of vascular endothelial growth factor (VEGF) have been reported in patients with cancers of different origins. There are no data comparing serum VEGF levels of medullary thyroid carcinoma (MTC) patients with that of the healthy subjects.

Objective: We tried to assess whether serum VEGF concentration in MTC patients is correlated with tumour extension and whether this marker might be used to further refine the selection of candidates for future therapies with receptor tyrosine kinase inhibitors.

Methods: Sera from 57 individuals divided into five groups: group I, healthy individuals $(n=14)$; group II, MTC patients in remission $(n=10)$; group III, MTC patients with residual disease $(n=12)$; group IV, MTC patients with loco-regional disease $(n=11)$ and group V, MTC patients with distant metastases $(n=10)$ were analysed for serum VEGF and calcitonin (CT) levels.

Results: Analysis of serum VEGF did not disclose significant differences among the five groups. Mean serum VEGF level of patients with distant metastases was not significantly different from that observed in healthy individuals $(319.4 \pm 49.78$ vs $313.7 \pm 43.13 \mathrm{ng} / \mathrm{l})$. Serum VEGF levels correlated positively with serum CT $(r=0.4891 ; P=0.0394)$ for CT values below $2500 \mathrm{ng} / \mathrm{l}$ whereas there was no correlation for CT values above this threshold.

Conclusions: Serum VEGF levels in MTC patients are not significantly different from those found in healthy individuals and did not correlate with the extension of disease.
\end{abstract}

European Journal of Endocrinology 159 167-169

\section{Introduction}

Medullary thyroid carcinoma (MTC) stems from calcitonin (CT)-producing parafollicular cells and accounts for less than 10\% of thyroid carcinomas (1). MTC metastasizes early via lymphatic and haematogenous routes. Currently, there is no effective systemic therapy.

The genetic hallmarks of MTC are gain-of-function mutations in the RET proto-oncogene (2). This gene encodes a transmembrane tyrosine kinase that is a member of the receptor tyrosine kinases (RTKs) family. Thus, RET became a target for genetic-orientated therapy of MTC patients with unresectable disease. Most of the promising inhibitors of growth factor receptor tyrosine kinases also inhibit the vascular endothelial growth factor receptor (VEGFR).

VEGF is a glycoprotein that promotes endothelial regeneration, stimulates formation of collateral blood vessels and increases vascular permeability. The VEGF family is composed of several isoforms (VEGF-A, VEGF-B, VEGF-C and VEGF-D) arising from tissue-specific alternative splicing of transcripts from a single VEGF gene. VEGF-A regulates vasculogenesis via two receptor tyrosine kinases: VEGFR1 and VEGFR2. VEGF-C is primarily involved in lymphangiogenesis and acts through VEGFR3 (3).

Increased tissue expression and high serum VEGF levels have been reported in patients with cancers of different origins (4-10) including patients with differentiated thyroid carcinoma (DTC) (11-13). Several reports suggest that the expression of VEGF by thyroid cancer cells is associated with a more aggressive phenotype in both animal models and clinical studies (14-16).

The expression of VEGF mRNA by MTC cells was first reported by Soh et al. (17) and confirmed by others $(18,19)$. There are no data comparing the serum VEGF levels of MTC patients with that of the healthy subjects.

Herein, we tried to assess whether serum VEGF concentration in MTC patients is correlated with tumour extension and whether this marker might be used, in the future, to further refine selection of candidates for therapy with RTK inhibitors. 


\section{Materials and methods}

\section{Samples}

We analysed samples from 57 individuals divided into five groups: group I, healthy subjects/blood donors $(n=14)$; group II, MTC patients in remission/undetectable serum CT levels and negative imaging exams $(n=10)$; group III, residual disease/measurable serum CT levels and negative imaging exams $(n=12)$; group IV, loco-regional disease $(n=11)$ and group $\mathrm{V}$, metastatic disease/distant metastases $(n=10)$.

MTC patients were recruited from the outpatient clinic of the Endocrine Department of the Portuguese Cancer Centre in Lisbon. None had co-morbidities such as diabetes mellitus, hypertension or heart failure and all were under treatment with laevothyroxine presenting normal thyrotrophin levels. The MTC diagnosis was established based on histological criteria following total thyroidectomy.

Serum VEGF levels were measured in all individuals. Serum CT levels were measured in MTC patients. The study was approved by the local ethics committee.

\section{Serum VEGF measurements}

Serum VEGF measurements were performed in batches using the Quantikine Human VEGF sandwich enzyme immunoassay (R\&D Systems, Minneapolis, MN, USA). The intra-assay precision, expressed as coefficients of variation, was $4.5-6.7 \%$; the inter-assay precision was $6.2-8.8 \%$ and the sensitivity was $<9 \mathrm{ng} / \mathrm{l}$. All assays were performed in duplicate.

\section{Serum CT measurements}

Serum CT measurement was performed using an IMA chemiluminescence assay (IMMULITE 2000, Diagnostic Products Corp., Los Angeles, CA, USA) calibrated against the second international RP 89/620. CT values of $<2 \mathrm{ng} / \mathrm{l}$ were regarded as undetectable.

\section{Statistical analysis}

Statistical analysis was carried out using GraphPad Prism statistical software (San Diego, CA, USA). Values were expressed as mean \pm s.E.M. Mean values were compared using the one-way ANOVA test plus Tukey's multiple comparison test. CT values were transformed to their logarithms to equalize the variances. Relationship among variables was sought using Spearman's rank order correlation coefficient. Statistical significance was accepted at $P<0.05$.

\section{Results}

As expected, serum CT levels were significantly different between MTC patients with detectable CT concentrations: group III versus IV, $P<0.001$; group III versus $\mathrm{V}, P<0.001$ and group IV versus V, $P<0.05$ (Table 1 ).

Analysis of serum VEGF levels did not disclose significant differences among the five groups (Table 1). Likewise, there was no significant correlation between serum CT and serum VEGF levels based on the analysis of groups III-V $(r=0.2623 ; P=0.1402)$. However, if we subdivide patients according to CT values, below and above $2500 \mathrm{ng} / \mathrm{l}$, in the former subgroup serum VEGF levels were positively correlated with serum CT levels $(n=18, \quad r=0.4891 ; P=0.0394)$, whereas there was no correlation in the latter subgroup $(n=15$, $r=-0.1395$; $P=0.6199$ ).

Patients with distant metastases (including three with only liver metastases, two with only lung metastases, two with liver+lung + bone metastases, two with liver + lung metastases and one with liver and bone metastases) did not differ significantly from the control group in terms of serum VEGF levels (319.4 \pm 49.78 vs $313.7 \pm 43.13 \mathrm{ng} / \mathrm{l})$.

The lowest serum VEGF levels were observed in groups II and III although they were not significantly different from the control group.

Table 1 Serum calcitonin and vascular endothelial growth factor (VEGF) levels (ng/l) in the five study groups.

\begin{tabular}{|c|c|c|c|c|c|}
\hline \multirow[b]{2}{*}{ Groups } & \multirow[b]{2}{*}{$n$} & \multicolumn{2}{|c|}{ Calcitonin (ng/l) } & \multicolumn{2}{|c|}{ VEGF (ng/l) } \\
\hline & & Mean \pm S.E.M. & Median (min-max) & Mean \pm S.E.M. & Median (min-max) \\
\hline I & 14 & - & - & $313.7 \pm 43.13$ & $326(69-632)$ \\
\hline II & 10 & - & - & $213.2 \pm 34.39$ & $195.5(67-387)$ \\
\hline III & 12 & $115.3 \pm 32.14$ & $61.8(11.7-354)$ & $223.3 \pm 36.13$ & $225(45-517)$ \\
\hline IV & 11 & $10571 \pm 3187$ & 4957 (237-34 194) & $364.5 \pm 51.82$ & $370(54-637)$ \\
\hline $\mathrm{V}$ & 10 & $39420 \pm 12466$ & 12466 (1269-118 312) & $319.4 \pm 49.78$ & $322(77-643)$ \\
\hline$P$ & & $<0.0001$ & & NS & \\
\hline
\end{tabular}

$n$, number of samples; NS, non-significant. $P$ values determined by one-way ANOVA test with Tukey's multiple comparison test (calcitonin: group III versus IV, $P<0.001$; group III versus $\mathrm{V}, P<0.001$; and group IV versus $\mathrm{V}, P<0.05$ ). To equalize variances, calcitonin values were transformed to their logarithms prior to statistical analysis. 


\section{Discussion}

VEGF promotes endothelial regeneration, formation of collateral blood vessels and vascular permeability. High serum VEGF levels have been reported in patients with cancers of different origins (4-10) including patients with thyroid carcinomas deriving from follicular cells (11-13). This study was designed to assess serum VEGF levels in MTC patients. Moreover, we wondered if this marker might be useful to refine selection of patients for future therapies with tyrosine kinase inhibitors, mainly those without RET mutations, since these molecules share a moderate affinity for RET, with equivalent or better affinity for VEGFR, in the low nanomolar range.

We concluded that serum VEGF levels in MTC patients are not significantly different from those found in healthy individuals and did not correlate with the extension of disease. Thus, the serum VEGF levels in MTC patients do not appear useful to select potential candidates for therapies with tyrosine kinase inhibitors.

Failure to demonstrate high levels of serum VEGF in MTC patients with distant metastases, in contrast to what happens in patients with DTC (13), suggests the involvement of other proangiogenic factors. Recently, Chigurupati et al. (20) have shown that prostate tumourderived CT, acting via CT receptor, may play an important role in prostate tumour growth by regulating intratumoral vascularization. We, therefore, wonder whether similar mechanisms might be implicated in MTC.

\section{Acknowledgements}

We are grateful to Mrs Sofia Alexandra Sabino Gomes for her expert technical assistance.

\section{References}

1 Sherman SI. Thyroid carcinoma. Lancet 2003361 501-511.

2 Santoro M, Melillo RM, Carlomagno F, Vecchio G \& Fusco A. RET: normal and abnormal functions. Endocrinology 2004145 5448-5451.

3 Mitchell JC \& Parangi S. Angiogenesis in benign and malignant thyroid disease. Thyroid 200515 494-510.

4 Inoue K, Ozeki Y, Suganuma T, Sugiura Y \& Tanaka S. Vascular endothelial growth factor expression in primary esophageal squamous cell carcinoma. Association with angiogenesis and tumor progression. Cancer 199779 206-213.

5 de Jong JS, van Diest PJ, van der Valk P \& Baak JP. Expression of growth factors, growth-inhibiting factors, and their receptors in invasive breast cancer. II: Correlations with proliferation and angiogenesis. Journal of Pathology 1998184 53-57.

6 Crew JP. Vascular endothelial growth factor: an important angiogenic mediator in bladder cancer. European Urology 1999 $352-8$.

7 Adams J, Carder PJ, Downey S, Forbes MA, MacLennan K, Allgar V, Kaufman S, Hallam S, Bicknell R, Walker JJ, Cairnduff F, Selby PJ, Perren TJ, Lansdown M \& Banks RE. Vascular endothelial growth factor (VEGF) in breast cancer: comparison of plasma, serum, and tissue VEGF and microvessel density and effects of tamoxifen. Cancer Research 200060 2898-2905.

8 Chin KF, Greenman J, Gardiner E, Kumar H, Topping K \& Monson J. Pre-operative serum vascular endothelial growth factor can select patients for adjuvant treatment after curative resection in colorectal cancer. British Journal of Cancer 200083 1425-1431.

9 Poon RT, Ng IO, Lau C, Zhu LX, Yu WC, Lo CM, Fan ST \& Wong J. Serum vascular endothelial growth factor predicts venous invasion in hepatocellular carcinoma: a prospective study. Annals of Surgery $2001233227-235$.

10 Ugurel S, Rappl G, Tilgen W \& Reinhold U. Increased serum concentration of angiogenic factors in malignant melanoma patients correlates with tumor progression and survival. Journal of Clinical Oncology 200119 577-583.

11 Tuttle RM, Fleisher M, Francis GL \& Robbins RJ. Serum vascular endothelial growth factor levels are elevated in metastatic differentiated thyroid cancer but not increased by short-term TSH stimulation. Journal of Clinical Endocrinology and Metabolism 200287 1737-1742.

12 Sorvillo F, Mazziotti G, Carbone A, Piscopo M, Rotondi M, Cioffi M, Musto P, Biondi B, Iorio S, Amato G \& Carella C. Recombinant human thyrotropin reduces serum vascular endothelial growth factor levels in patients monitored for thyroid carcinoma even in the absence of thyroid tissue. Journal of Clinical Endocrinology and Metabolism $2003 \mathbf{8 8} 4818-4822$.

13 Klubo-Gwiezdzinska J, Junik R, Kopczynska E, Juraniec O \& Kardymowicz $\mathrm{H}$. The comparison of serum vascular endothelial growth factor levels between patients with metastatic and nonmetastatic thyroid cancer, and patients with nontoxic multinodulargoiter. European Journal of Endocrinology 2007157 521-527.

14 Klein M, Picard E, Vignaud JM, Marie B, Bresler L, Toussaint B, Weryha G, Duprez A \& Leclère J. Vascular endothelial growth factor gene and protein: strong expression in thyroiditis and thyroid carcinoma. Journal of Endocrinology 1999161 41-49.

15 Lennard CM, Patel A, Wilson J, Reinhardt B, Tuman C, Fenton C, Blair E, Francis GL \& Tuttle RM. Intensity of vascular endothelial growth factor expression is associated with increased risk of recurrence and decreased disease-free survival in papillary thyroid cancer. Surgery 2001129 552-558.

16 Klein M, Vignaud JM, Hennequin V, Toussaint B, Bresler L, Plénat F, Leclère J, Duprez A \& Weryha G. Increased expression of the vascular endothelial growth factor is a pejorative prognosis marker in papillary thyroid carcinoma. Journal of Clinical Endocrinology and Metabolism 200186 656-658.

17 Soh EY, Duh QY, Sobhi SA, Young DM, Epstein HD, Wong MG, Garcia YK, Min YD, Grossman RF, Siperstein AE \& Clark OH. Vascular endothelial growth factor expression is higher in differentiated thyroid cancer than in normal or benign thyroid. Journal of Clinical Endocrinology and Metabolism $1997 \mathbf{8 2}$ 3741-3747.

18 Bunone G, Vigneri P, Mariani L, Butó S, Collini P, Pilotti S, Pierotti MA \& Bongarzone I. Expression of angiogenesis stimulators and inhibitors in human thyroid tumors and correlation with clinical pathological features. American Journal of Pathology 1999155 1967-1976.

19 de la Torre NG, Buley I, Wass JA \& Turner HE. Angiogenesis and lymphangiogenesis in thyroid proliferative lesions: relationship to type and tumour behaviour. Endocrine-Related Cancer 200613 931-944.

20 Chigurupati S, Kulkarni T, Thomas S \& Shah G. Calcitonin stimulates multiple stages of angiogenesis by directly acting on endothelial cells. Cancer Research 200565 8519-8529.

Received 22 April 2008

Accepted 29 April 2008 